\title{
BMJ Global Health Humane shelter at home: a call to reimagine a core pandemic intervention
}

\author{
Ramnath Subbaraman (1) , ${ }^{1,2}$ Lakshmi Ganapathi (1) , ${ }^{3}$ Bhramar Mukherjee (D) , \\ David E Bloom (iD) , ${ }^{5}$ Sunil Suhas Solomon (i) ${ }^{6,7}$
}

To cite: Subbaraman $\mathrm{R}$,

Ganapathi L, Mukherjee B, et al. Humane shelter at home: a call to reimagine a core pandemic intervention. BMJ Global Health 2021;6:e006614. doi:10.1136/ bmjgh-2021-006614

Handling editor Seye Abimbola

Received 14 June 2021 Accepted 23 July 2021

Check for updates

C Author(s) (or their employer(s)) 2021. Re-use permitted under CC BY-NC. No commercial re-use. See rights and permissions. Published by BMJ.

For numbered affiliations see end of article.

Correspondence to Dr Ramnath Subbaraman; ramnath.subbaraman@tufts.edu

\section{INTRODUCTION}

The devastating second wave of India's COVID-19 pandemic has understandably provoked international outcry to accelerate vaccine rollout in low-income and middleincome countries (LMICs). The global vaccine rollout is indeed paramount and represents the most promising path out of this pandemic. At the same time, India's second wave shows that vaccine distribution may not happen fast enough to avert catastrophic COVID-19 surges in LMICs. As in India, countries as varied as Nepal, Tunisia, Malaysia and Uganda have experienced recent surges, with warnings of imminent health system collapse and oxygen shortages similarly reverberating. ${ }^{1-3}$ In the near term, LMICs will not be able to treat or vaccinate themselves out of surges without great loss of life. Instead, saving lives will require competent implementation of public health measures that have been mainstays of combating this pandemic since its emergence. In the wake of India's tragedy, we propose reimagining one such measure-sometimes referred to as 'lockdown'-and, in place of this language that evokes painful memories for millions, argue for a new concept: humane shelter at home (HuSH).

We argue for this shift in language not as a matter of semantics, but rather to motivate critical rethinking of when and how this measure should be used to save lives. In LMICs, the calculus for lockdowns is even narrower than in high-income countries. LMIC governments fear that starvation deaths-rather than unemployment and psychosocial distress alone-could be the worst consequence of poorly implemented lockdowns, and yet, as India's situation reveals, inaction or delay in implementing lockdowns may be even more detrimental.

\section{THE HIGH COSTS OF DELAY}

Last year's nationwide lockdown in India, instituted from March to May 2020, curbed
Summary box

The second wave of India's COVID-19 pandemicand recent waves in other countries-shows that vaccine distribution may not happen fast enough to avoid catastrophic new surges.

- Due to the societal costs of a nationwide lockdown in 2020, the national government and state governments in India delayed implementing lockdowns during the second wave, resulting in the highest short-term COVID-19 case numbers and deaths witnessed globally during this pandemic.

- Lockdowns are highly effective in curbing COVID-19 transmission and averting deaths if implemented early; however, the term lockdown evokes painful memories, considering the inhumane ways this intervention has been implemented.

- We argue for reimagining 'lockdown' by instead using the term 'humane shelter at home' (HuSH) to emphasise this intervention's public health benefits and the need for robust social protections to mitigate adverse impacts for vulnerable populations.

- HuSH should be a central concept for pandemic preparedness, and the WHO, donor governments and multilateral lending institutions should provide technical assistance and develop funding mechanisms to ensure this intervention can be implemented rapidly and humanely.

COVID-19 transmission ${ }^{4}$; however, memories of its societal costs coloured India's response to the second wave. On 24 March 2020, the entire country was given 4 hours' notice to return home and stay in place. Although the central government implemented a financial stimulus and state governments provided food via India's public distribution system (PDS, a network of ration shops), vulnerable populations, particularly migrant workers, were sometimes excluded from these benefits. Public transportation was abruptly suspended. Facing unemployment in cities, migrant workers sometimes walked hundreds of kilometres back to rural areas. Journalists directly attributed hundreds of deaths to the lockdown. ${ }^{5}$ Healthcare provision suffered, 
evidenced by drops in tuberculosis notifications, ${ }^{6}$ HIV testing $^{7}$ and child vaccinations. ${ }^{8}$ The lockdown's disproportionate costs for India's vulnerable, as well as the perception that COVID-19 may be less severe in poor countries than in wealthy countries, led some public health specialists with expertise in India to argue that lockdowns are relevant to high-income countries but misaligned with challenges facing LMICs. ${ }^{8}$

India's second wave, which began in March 2021, has revealed important limitations of this argument. This surge likely resulted from breakdown in social distancing behaviours, including large political and religious gatherings, and spread of the more transmissible delta and alpha variants. In April 2021, as transmission escalated beyond what less aggressive measures could control, national and state governments debated whether lockdowns should occur. The central government deferred decisions to state governments. Paralysed by a seemingly no-win situation, states delayed instituting lockdowns. Instead, most implemented ineffective transmission control measures, including night curfews, weekend restrictions or partial workplace capacity reductions. ${ }^{910}$ As hospital bed availability shrank, oxygen supplies dwindled and deaths escalated, state governments were forced to institute lockdowns in extremis. The central problem was not that states did not initiate lockdowns, but rather that they did not initiate them early. ${ }^{11}$ The consequences of delay have been devastating: India frequently reported over 350000 cases and 3000 deaths daily from late-April to mid-May, likely representing substantial undercounts of true infections and deaths. ${ }^{12}$ Lockdowns and their economic and social costs were not averted, but instead were imposed during medical crises, reducing governments' bandwidth to provide social protections.

\section{EFFECTIVE WHEN IMPLEMENTED EARLY}

India's crisis happened despite evidence showing lockdowns have been highly effective-in China, Europe and the USA, for example-in reducing COVID-19 transmission and saving lives. ${ }^{13-17}$ Moreover, early intervention is critical to quell spread of pandemic respiratory viruses locally and across regions in large countries. During the 1918 influenza pandemic in the USA, St. Louis implemented multiple social distancing measures only 14 days earlier than Philadelphia, relative to when initial cases occurred in each city, but experienced less than half of Philadelphia's cumulative influenza-related mortality. ${ }^{18}$ Locking down Wuhan just 3 days earlier might have reduced COVID-19 infections in the rest of China by nearly half. ${ }^{13}$ In India's second wave, cities like Delhi and Mumbai that implemented the earliest and most effective lockdowns witnessed rapid plateaus in case counts, which then dropped considerably faster than the rest of India, where lockdowns were initiated later or less comprehensively (figure 1).

Scientific advances in COVID-19 therapies and vaccines are clearly important but could lead to a false sense of security and shift focus away from public health measures that more effectively save lives during acute surges. The few effective COVID-19 therapies, such as dexamethasone, result in only small reductions in absolute mortality for the overall population. Vaccines are highly effective at preventing disability and death; however, vaccination coverage is lagging in LMICs: as of 16 July 2021, out of 1.3 billion people living in African countries, only about $1 \%$ are fully vaccinated. ${ }^{3}$ Even the most efficient vaccination campaigns move too slowly to have a meaningful impact during COVID-19 surges, particularly in the context of the delta and alpha variants, which have changed the dynamics of the pandemic, given their higher transmissibility. ${ }^{19}$ Conversely, lockdowns buy time to advance the vaccine rollout, which portends an end to this pandemic. By curbing transmission, lockdowns may also slow the emergence of additional variants that could be more transmissible or reduce vaccine efficacy, thereby allowing time for development of vaccine boosters if needed.
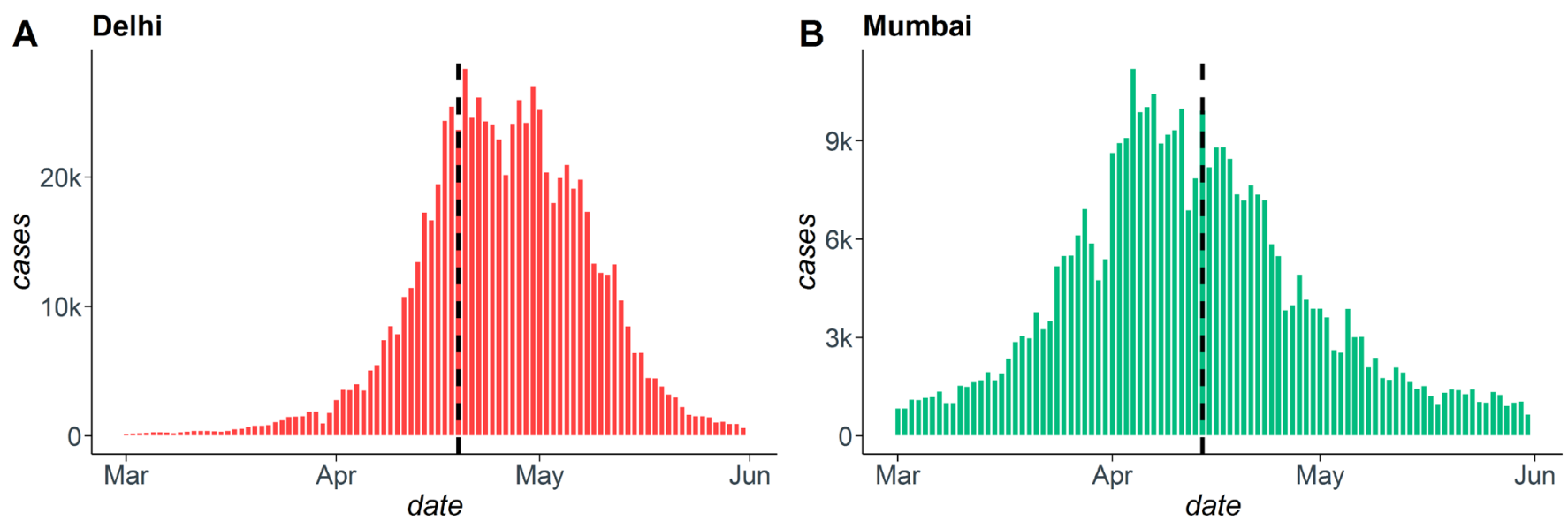

Figure 1 COVID-19 daily case numbers for Delhi and Mumbai, India, from 1 March to 31 May 2021. Dotted lines indicate the dates that comprehensive lockdowns were implemented on 19 April for Delhi and 14 April for Mumbai. By 31 May, case numbers had declined by $97 \%$ and $94 \%$ from their peaks in Delhi and Mumbai,respectively. By contrast, overall case numbers in India declined by only $69 \%$ from their peak by 31 May (data from covind19.org). 
Although lockdowns put vulnerable populations at risk, evidence globally suggests these same populations suffer disproportionately from uncontrolled transmission, especially given suboptimal healthcare access. Modelling analyses also suggest that, by containing transmission quickly, early implementation of lockdowns may lead to faster economic recovery. ${ }^{20}$

Our intention is not to minimise the importance of public health interventions that could prevent the need for lockdowns-including testing, contact tracing and isolation. However, when these measures fail, early lockdowns may be effective, especially where health systems are weak.

\section{REIMAGINING LOCKDOWN}

Given their effectiveness, we believe lockdowns should be reimagined from three perspectives. First, we should reimagine the language used to describe this intervention. The word lockdown evokes images of government repression. By contrast, 'shelter' alludes to the idea that staying home protects individuals from infection during widespread community transmission. The word 'humane' indicates social protections are central to this intervention rather than just an afterthought. This language shift is also pragmatic; aversion to the word lockdown in India possibly delayed implementation of this life-saving intervention.

We should also reimagine and define the components of $\mathrm{HuSH}$ that most effectively reduce transmission using the latest evidence. Guidance might emphasise the importance of evacuating high-risk indoor spacesincluding workplaces, restaurants, religious spaces and non-essential shopping establishments-rather than instituting punitive measures for non-congregative, low-risk outdoor activities. Wide-scale distribution of high-quality face masks, especially for essential workers, should happen concurrently. International bodies, such as the WHO, should create guidance on best practices for implementing HuSH. With the absence of such guidance, Indian state governments suffered economic losses from implementing highly variable and often ineffective social distancing measures while missing out on the health benefits of early HuSH. Across different African countries, implementation of social distancing measures has also been highly variable, highlighting a need for evidence-based guidance. $^{21}$

Most importantly, we should reimagine and provide international support for the social protections necessary to ensure shelter at home is implemented humanely, especially, but not exclusively, in LMICs. Recent efforts of some Indian states provide examples of how to institute social protections. After issuing shelter at home orders in May 2021, Tamil Nadu initiated cash transfers to much of the population, while Kerala opened community kitchens, delivered food kits to migrant workers and provided rations through the PDS. Expansion of social protection schemes to reach the most vulnerable populations, such as migrant workers, should be a central component of $\mathrm{HuSH}$.

HuSH may be easier to achieve in high-income countries, and implementation capacity within large LMICs, such as India, may be variable by state or region. As such, to facilitate $\mathrm{HuSH}$, donor governments and multilateral lending institutions should expand their vision beyond provision of vaccines, oxygen and medical equipment. They should offer countries technical support regarding early escalation of social distancing measures and financial assistance for social protections, including food aid and cash transfers. They should support rapid scale-up of testing and surveillance, so that LMICs can safely relax social distancing measures. International mechanisms need to be created for rapid disbursal of funds to support $\mathrm{HuSH}$, through a multilateral global pandemic fund or as part of the WHO Director-General's call for a global pandemic treaty. Since HuSH may be a crucial intervention during future pandemics, developing funding strategies now may serve as an enduring investment in global health.

\section{CONCLUSION}

The daunting reality of new waves of the COVID-19 pandemic in LMICs underscores the imperative to accelerate the global vaccine rollout. At the same time, before high levels of vaccine coverage can be achieved globally, all countries, and LMICs in particular, are still at risk of experiencing devastating COVID-19 waves. HuSH must be a core part of the agenda for addressing a pandemic that is still too far from ending, so that the tragedy of India's second wave is not repeated elsewhere.

\section{Author affiliations}

${ }^{1}$ Department of Public Health and Community Medicine and Center for Global Public Health, Tufts University School of Medicine, Boston, Massachusetts, USA

${ }^{2}$ Division of Geographic Medicine and Infectious Diseases, Tufts Medical Center, Boston, Massachusetts, USA

${ }^{3}$ Division of Infectious Diseases, Boston Children's Hospital and Harvard Medical School, Boston, Massachusetts, USA

${ }^{4}$ Departments of Biostatistics, Epidemiology, and Global Public Health, University of Michigan, Ann Arbor, Michigan, USA

${ }^{5}$ Department of Global Health and Population, Harvard T.H. Chan School of Public Health, Boston, Massachusetts, USA

${ }^{6}$ Department of Medicine, Johns Hopkins University School of Medicine, Baltimore, Maryland, USA

${ }^{7}$ YR Gaitonde Centre for AIDS Research and Education (YRGCARE), Chennai, Tamil Nadu, India

Twitter Lakshmi Ganapathi @Lakshmi_RKG, Bhramar Mukherjee @BhramarBioStat, David E Bloom @DavidEBloom and Sunil Suhas Solomon @sss_cubed

Contributors RS and LG prepared the initial manuscript draft, with feedback from SSS. DEB, SSS and BM provided feedback on subsequent revisions of the manuscript. BM analysed the data and created the figure. All authors approved the final version of the manuscript.

Funding RS is supported by a Doris Duke Clinical Scientist Development Award (grant number 2018095). LG is supported by a Thrasher Research Fund Early Career Award, a Harvard University Center for AIDS Research Developmental Award (P30 Al060354) and the Aerosmith Endowment Fund (Boston Children's Hospital). SSS is supported by a NIDA Avenir Award (DP2DA040244).

Competing interests None declared. 
Patient consent for publication Not required.

Provenance and peer review Not commissioned; externally peer reviewed.

Data availability statement Data for the figure were accessed from covind19. org, which uses covid19india.org--a public, open access repository--as its data source for COVID-19 case counts in India. Data used to create this specific figure are also available upon request from bhramar@umich.edu.

Open access This is an open access article distributed in accordance with the Creative Commons Attribution Non Commercial (CC BY-NC 4.0) license, which permits others to distribute, remix, adapt, build upon this work non-commercially, and license their derivative works on different terms, provided the original work is properly cited, appropriate credit is given, any changes made indicated, and the use is non-commercial. See: http://creativecommons.org/licenses/by-nc/4.0/.

\section{ORCID iDs}

Ramnath Subbaraman http://orcid.org/0000-0002-2063-943X

Lakshmi Ganapathi http://orcid.org/0000-0001-5055-0834

Bhramar Mukherjee http://orcid.org/0000-0003-0118-4561

David E Bloom http://orcid.org/0000-0003-3731-3345

Sunil Suhas Solomon http://orcid.org/0000-0002-0506-8122

\section{REFERENCES}

1 Bhandari R, Ellis-Peterson H. A hopeless situation': oxygen shortage fuels Nepal's Covid crisis. The Guardian, 2021. Available: https:// www.theguardian.com/world/2021/may/10/hopeless-situationoxygen-shortage-fuels-nepal-covid-crisis [Accessed 8 Jun 2021].

2 Schaer C, Knipp K. Tunisia's third Covid-19 wave: Doctors warn of health system collapse. Deutsche Welle, 2021. Available: https:// www.dw.com/en/tunisia-covid-19-doctors-warn-of-health-systemcollapse/a-57425281 [Accessed 8 Jun 2021].

3 Dahir AL, Holder J. Africa's Covid crisis deepens, but vaccines are still far off. The New York Times, 2021. Available: https://www. nytimes.com/interactive/2021/07/16/world/africa/africa-vaccinationrollout.html [Accessed $16 \mathrm{Jul} 2021$ ].

4 Salvatore M, Basu D, Ray D, et al. Comprehensive public health evaluation of lockdown as a non-pharmaceutical intervention on COVID-19 spread in India: national trends masking state-level variations. BMJ Open 2020;10:e041778.

5 Sharma K. One year later, remembering the deaths and devastation India's lockdown left behind. The Wire, 2021. Available: https:// thewire.in/rights/india-coronavirus-lockdown-deaths-inequality [Accessed 8 Jun 2021].

6 Shrinivasan R, Rane S, Pai M. India's syndemic of tuberculosis and COVID-19. BMJ Glob Health 2020;5:e003979.
7 Enugu AK, Thakkar J, Ghosh S, et al. Covid-19 impact on index testing services in 5 high HIV prevalence Indian districts [abstract 145]. Conference on Retroviruses and Opportunistic Infections, 2021. Available: https://www.croiconference.org/abstract/covid-19impact-on-index-testing-services-in-5-high-hiv-prevalence-indiandistricts/ [Accessed 8 June 2021].

8 Cash R, Patel V. Has COVID-19 subverted global health? Lancet 2020;395:1687-8.

9 Dimeglio C, Miedougé M, Loubes J-M, et al. Side effect of a 6 p.m curfew for preventing the spread of SARS-CoV-2: a modeling study from toulouse, France. J Infect 2021;82:186-230.

10 Haas S, Gotz G, Heim S. Measuring the effects of Covid-19-related night curfews: empirical evidence from Germany. MAGKS Papers on Economics 202118 [preprint], 2021. Available: https://ideas.repec. org/p/mar/magkse/202118.html [Accessed 8 Jun 2021].

11 Salvatore M, Bhattacharyya R, Purkayastha S. Resurgence of SARSCoV-2 in India: potential role of the B.1.617.2 (delta) variant and delayed interventions. medRxiv 2021.

12 Purkayastha S, Kundu R, Bhaduri R, et al. Estimating the wave 1 and wave 2 infection fatality rates from SARS-CoV-2 in India. BMC Res Notes 2021;14:262 https://www.medrxiv.org/content/

13 Yuan Z, Xiao Y, Dai Z, et al. Modelling the effects of Wuhan's lockdown during COVID-19, China. Bull World Health Organ 2020;98:484-94.

14 Flaxman S, Mishra S, Gandy A, et al. Estimating the effects of non-pharmaceutical interventions on COVID-19 in Europe. Nature 2020;584:257-61.

15 Hsiang S, Allen D, Annan-Phan S, et al. The effect of large-scale anti-contagion policies on the COVID-19 pandemic. Nature 2020;584:262-7.

16 Islam N, Sharp SJ, Chowell G, et al. Physical distancing interventions and incidence of coronavirus disease 2019: natural experiment in 149 countries. BMJ 2020;370:m2743.

17 Vinceti M, Filippini T, Rothman KJ, et al. Lockdown timing and efficacy in controlling COVID-19 using mobile phone tracking. EClinicalMedicine 2020;25:100457.

18 Hatchett RJ, Mecher CE, Lipsitch M. Public health interventions and epidemic intensity during the 1918 influenza pandemic. Proc Nat Acad Sci U S A 2007;104:7582-7.

19 Li B, Deng A, Li K. Viral infection and transmission in a large welltraced outbreak caused by the delta SARS-CoV-2 variant. medRxiv $20212021 ; 21260122$

20 International Monetary Fund. World economic outlook: a long and difficult ascent, 2020. Available: https://www.imf.org/en/ Publications/WEO/Issues/2020/09/30/world-economic-outlookoctober-2020 [Accessed 16 Jul 2021].

21 Haider N, Osman AY, Gadzekpo A, et al. Lockdown measures in response to COVID-19 in nine sub-Saharan African countries. BMJ Glob Health 2020;5:e003319. 